\title{
É possivel uma sociologia do sujeito? Uma abordagem sobre as teorias de Foucault e Touraine
}

NESUA FURLIN"

\section{Resumo}

Este ensaio de pesquisa analisa as concepções teóricas da noção de sujeito nas obras de dois intelectuais franceses, Touraine e Foucault. Trata-se de uma abordagem comparativa, na qual se busca estabelecer uma relação entre os aspectos que convergem e se distinguem na teoria social desses autores, procurando refletir sobre as suas contribuições para a compreensão da sociedade contemporânea, especificamente no que tange aos processos de subjetivação dos indivíduos. Em razão disso, selecionaram-se as últimas obras da trajetória acadêmica desses intelectuais. Tanto Touraine como Foucault apontam contribuições teóricas para uma sociologia que não recorre aos grandes fenômenos históricos, mas que coloca em cena o esforço do sujeito no interior das microrrelações sociais, em suas contradições culturais, econômicas, políticas e pessoais.

Palavras-chave: Sociologia do sujeito. Teoria social. Sociedade contemporânea.

* Doutoranda pelo Programa de Pós-Graduação em Sociologia da Universidade Federal do Paraná (Brasil) e Bolsista da CAPES/REUNI. É membro do Núcleo de Estudos de Gênero da Universidade Federal do Paraná. E-mail: nfurlin@yahoo.com.br 


\title{
Is a Sociology of the subject possible? An approach to the theories of Foucault and Touraine
}

\begin{abstract}
This research essay analyzes the theoretical concepts of the notion of "subject" in the works of two French intellectuals, Touraine and Foucault. This comparative approach seeks to establish a relation between the convergent and the contrasting aspects of their social theories, on the purpose of reflecting on their contributions to the comprehension of contemporary society, especially concerning individuals' subjectivation processes. For this purpose we chose the last works in the scholarly trajectory of these intellectuals. Touraine as well as Foucault offer theoretical contributions to a sociology that does not resort to the great historical phenomena, but puts the efforts of the subjects within their social micro-relations on the stage, considering their cultural, economic, political and personal contradictions.
\end{abstract}

Keywords: Sociology of the subject. Social Theory. Contemporary Society.

\section{Introdução}

O sentido da vida humana somente brota da própria definição pelos seres humanos, daquilo que é humano, que é respeitoso ao direito de cada indivíduo em todos os domínios de sua vida pessoal. (Touraine, 2009, p. 240)

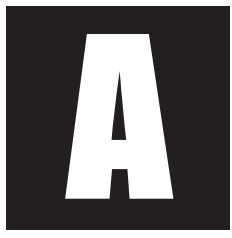

relação entre indivíduo e sociedade tem sido uma das preocupações centrais na teoria sociológica. Entretanto, as transformações socioculturais impulsionaram um processo de mudança na forma como o indivíduo foi sendo compreendido na trama das relações sociais. Hoje as instituições sociais e políticas já não exercem mais total influência na formação dos indivíduos. Por isso, na concepção de Touraine, a análise social não pode mais ter como principal objetivo a sociedade (instituições), mas os atores, os quais são mais do que sociais, pois não são definidos 
somente pelas suas pertenças e relações sociais, mas também pelos direitos culturais.

Nessa perspectiva, o presente artigo pretende analisar as concepções teóricas da noção de sujeito nas obras de dois intelectuais franceses, Touraine e Foucault. Trata-se de uma abordagem comparativa, na qual se busca estabelecer uma relação entre os aspectos que convergem e se distinguem na teoria social desses autores. Essa escolha se deve ao fato de que nas obras desses autores a ideia do sujeito é central e, em alguns pontos, parece haver aproximações em suas concepções teóricas. Portanto, o esforço é buscar perceber até que ponto existe uma convergência nas noções de sujeito elaboradas por esses intelectuais, no intuito de refletir sobre as suas contribuições para a compreensão da ação social em face das instituições nas sociedades modernas.

O próprio Touraine (2009) menciona Foucault como uma das figuras mais importantes e, até mesmo, a mais eminente dos últimos tempos, por ter construído um pensamento que deu uma reviravolta no discurso dominante, uma vez que a noção de sujeito ocupa um espaço central em sua obra. Por isso, confessa que se sentiu encorajado a construir um pensamento oposto ao dominante quando se deparou com a última parte da obra de Foucault, escrita na segunda metade da década de $1970^{2}$. Para Touraine,

Michel Foucault nada mais é que o grande barqueiro. Este, partindo de sua oposição a Sartre, e atravessando os maiores temas do discurso interpretativo, alcança a idéia de sujeito e de subjetivação que nos liberta do sufoco imposto

\footnotetext{
1 Essa menção a Foucault aparece no livro Pensar Outramente: o discurso interpretativo dominante.

2 Para Touraine (2009), o pensamento de Foucault das obras: Vigiar e Punir e As palavras e as coisas ocupou lugar dentro do que ele chama de pensamento dominante. Entretanto, considera que Foucault foi, também, um dos principais críticos desse pensamento quando construiu outra noção de sujeito, já no final de sua trajetória intelectual.
} 
pela noção de uma sociedade sem atores, sem reflexão e sem consciência. (Touraine, 2009, p. 101)

Ao mencionar Foucault como um grande inovador, Touraine afirma que sua reflexão se cruza com o pensamento foucaultiano construído nos últimos anos de sua trajetória intelectual. Por isso, neste artigo elencamos aspectos gerais sobre as noções de sujeito presentes no pensamento desses dois autores. Em Foucault, destacamos a ideia de sujeito ético ${ }^{3}$ elaborada no último momento de sua trajetória intelectual, sobretudo nos volumes II e III da História da Sexualidade. E, em Touraine, destacamos a noção de sujeito pessoal presente em duas das suas últimas obras publicadas no Brasil: Um novo Paradigma para compreender o mundo hoje e Pensar Outramente: o discurso interpretativo dominante.

\section{Considerações sobre a abordagem de Michel Foucault}

Michel Foucault tem tido importância nas análises dos fenômenos sociais contemporâneos, já que suas ferramentas teóricas possibilitam compreender a sociedade a partir de realidades microssociais, permitindo articular processos sociais, ação e comportamento dos indivíduos. Pela pluralidade metodológica com que esse autor constrói o conhecimento, ele acaba transitando em diferentes áreas do saber acadêmico.

De acordo com Inês Lacerda Araujo (2008), Foucault não é um estruturalista e nem um pensador pós-moderno. Ele pode ser incluído entre os filósofos da linha contextualista hermenêutica e pragmática. Seus escritos percorrem a história desde o século XVI até os nossos dias. Na verdade, Foucault recua do presente para o passado com a intenção de

3 Em Foucault, o sujeito se constitui como ético quando é capaz de se posicionar de forma crítica diante do estabelecido, sem negar que o poder discursivo teve influência em sua própria vida. (Cf. Bluter, p.169) 
compreender os modos como fomos sendo constituídos como sujeitos. O seu interesse é compreender a sociedade contemporânea no contexto da sociedade francesa. Sua obra é marcada pela influência do pensamento do filósofo Nietzsche.

Um dos destaques do pensamento de Foucault foi o seu conceito de poder, pensado não como algo situado ou fixado nas estruturas estatais ou jurídicas, mas funcionando nas malhas das relações humanas e, por isso, disseminado nas estruturas sociais. Segundo Lacerda (2008), não se pode pensar as relações de poder em Foucault sem a sua relação com os campos de saberes e nem os saberes isentos de poder. O sujeito não se encontra livre dessas relações saber/poder, uma vez que ele é atravessado por elas. Foucault mostra como saber e poder se articulam e, por meio de práticas discursivas, atuam sobre os corpos dos indivíduos, produzindo um sujeito objetivado por práticas normalizadoras, corretivas ou punitivas. Foucault quer mostrar que há um outro tipo de poder que, longe de reprimir ou abstrair, produz verdade sobre o indivíduo em cada relação sua com o saber, poder esse derivado do exame, da vigilância e da normalização (Lacerda, 2008, p.82). Ele denomina esses mecanismos disciplinares como tecnologias de poder, que são pequenos procedimentos que tornam os indivíduos disciplinados ${ }^{4}$.

Foucault (1999) se utiliza da genealogia como um método que permite evidenciar as singularidades dos acontecimentos históricos e a forma como as relações de saber e de poder foram produzindo subjetividades nos indivíduos. Para Revel (2005), a metodologia genealógica nos permite apreender, de maneira coerente, todo o trabalho de Foucault, desde os seus primeiros escritos até os últimos, em que se evidenciam três domí-

4 A sua concepção de microfísica de poder não exclui as formas de poder mais clássicas e macrossociais presentes no Estado e nos sistemas jurídicos. 
nios possíveis de genealogias, ou as diferentes formas pelas quais nós nos constituímos sujeitos:

uma ontologia histórica de nós mesmos em nossas relações com a verdade, que permite nos construirmos como sujeitos do conhecimento; nas nossas relações com o campo do poder, que permite nos construirmos como sujeitos que agem sobre os outros; e em nossas relações com a moral, que permite nos construirmos como agentes éticos" (Revel, 2005, p. 53).

Segundo a autora, essas diferentes formas estão presentes em quase todas as obras de Foucault, mesmo que aparentemente confusas. Elas evidenciam os três modos de subjetivação que transformam os seres humanos em sujeitos, e isso revela que o tema central de sua obra não são as relações entre saber e poder, mas o sujeito. Por meio da genealogia do sujeito, ele mostra a existência de três práticas. As práticas discursivas ${ }^{5}$ desempenham o papel de produtoras epistêmicas, as práticas objetivantes ou disciplinares ${ }^{6}$ permitem pensar o sujeito no meio das ciências, cujo objeto é o indivíduo normalizável e, nas práticas subjetivantes ${ }^{7}$, o sujeito pode se pensar como sujeito (Lacerda, 2008, p. 93). Essas práticas correspondem, respectivamente, aos eixos nos quais o sujeito se constitui: o saber, o poder e a ética, ou, dito de outra maneira, nas relações com a verdade, com os outros e consigo mesmo. Foucault compreende que nesses domínios se exercem tanto práticas de dominação quanto práticas de liberdade. Isso indica que na ontologia histórica de nós mesmos fomos constituídos como sujeitos que exercem e sofrem relações de poder, e como sujeitos morais de nossas ações (Foucault, 2007b, p. 351).

5 Essas práticas são evidentes, sobretudo, na sua obra As palavras e as coisas, publicada em 1966.

6 As práticas disciplinares aparecem, principalmente, na obra Vigiar e punir, publicada em 1975.

7 As práticas subjetivantes são descritas no segundo e terceiro volume da História da Sexualidade, publicados em 1984. 
Na teoria foucaultiana, o Estado moderno não sufoca o indivíduo, mas coloca na sociedade micropoderes que impedem ao indivíduo escapar das tramas do poder. Assim, ao mesmo tempo em que dá espaço para a liberdade dos indivíduos para que estes se pensem como sujeitos livres, donos do seu destino, senhores dos seus atos, a sociedade age com mecanismos estabilizadores e fortalecedores da trama social que não esmagam, mas produzem indivíduos sujeitos e sujeitados, por meio das práticas disciplinares que articulam poder e saber.

Na última fase do seu pensamento, Foucault se dedica a pensar nas tecnologias de subjetivação ética. Concebe que as tecnologias de saber/ poder, que são tecnologias de dominação, e as tecnologias do eu, que produzem o indivíduo e os grupos governáveis, também produzem focos de resistência, pelos quais os grupos e os indivíduos podem operar transformações. É nesse espaço de liberdade e de resistência que o sujeito pode se constituir como sujeito ético.

\subsection{A noção de sujeito ético em Michel Foucault}

No final de sua trajetória acadêmica, Foucault desenvolve a reflexão sobre o sujeito ético, como uma das formas pelas quais se dá a constituição do sujeito no interior dos domínios do saber e do poder. Para isso, ele constrói uma genealogia do sujeito e da verdade, produzida por meio de práticas subjetivadoras, partindo das questões que envolvem os prazeres, na tradição grega ${ }^{8}$, e da experiência em torno da sexualidade dos latinos, do primeiro século da era cristã ${ }^{9}$, mostrando como essas práticas,

8 No II volume da História da Sexualidade, Foucault estuda os prazeres da tradição grega a partir do século IV a. C.

9 É bom lembrar que no volume I da História da Sexualidade, Foucault constrói uma genealogia sobre o dispositivo da sexualidade e a produção da verdade sobre o sujeito, que vai do tempo do exame da confissão do século VI até os dias de hoje. O discurso da sexualidade, que, inicialmente, era de propriedade da confissão cristã, passa dos confessionários para ciên- 
que, posteriormente, passaram pela prática confessional, se aproximam das práticas da cultura moderna ${ }^{10}$. Foucault mostra que na modernidade as práticas de si, as quais permitem a constituição da subjetividade, não dispensam as ciências, especialmente, a da sexualidade. Isso porque o conhecimento de si passa por meio de práticas médicas, psicanalíticas e psicológicas. Na verdade, a genealogia da nossa subjetividade moderna visa mostrar como acabamos por nos constituir enquanto sujeitos a partir de práticas de si, quer dizer, por meio de elaborações éticas da vida [...] (Lacerda, 2008, p. 135).

Mais do que avaliar as práticas morais da tradição grega ou da pastoral cristã, Foucault esteve interessado em mostrar o modo como o indivíduo se constitui em sujeito moral. Isto é, como para se reconhecer-se precisou questionar a sua conduta sexual, a maneira como encarava os prazeres e as práticas com preocupações éticas, que eram assumidas na relação de si.

Essa relação de si para consigo, formadora da subjetividade, implica uma ética que se imprime por atos de liberdade e de resistência política, tão necessária nos nossos dias.

[...] é possível suspeitar que haja certa impossibilidade de constituir hoje uma ética do eu, quando talvez seja esta uma tarefa urgente, fundamental, politicamente indispensável, se for verdade que, afinal, não há outro ponto, primeiro e último, de resistência ao poder político senão a relação de si para consigo mesmo. (Foucault, 2004, p. 306)

cia. Os discursos sobre a sexualidade passam a ser enunciados nos consultórios de médicos e psicólogos, depois nas práticas pedagógicas até chegar às relações cotidianas. Foucault mostra que esses discursos, por onde perpassam as dinâmicas de poder e saber, mais que reprimir os indivíduos, produzem uma verdade de si. Ou seja, ao mesmo tempo em que produzem sujeitos de saber e objetivam sujeitos, contribuem para a construção da verdade sobre si mesmo. 10 Foucault chama as regras de conduta e técnicas de autodomínio de técnicas de si. 
Um indivíduo pode conduzir a sua própria vida assumindo diferentes direções no ato de construir-se como sujeito moral de uma ação. A ética corresponde a uma "substancia ética", ou seja,

A maneira pela qual um indivíduo faz de si mesmo a matéria principal de sua conduta moral, da mesma maneira, ela implica necessariamente um modo de sujeição, isto é, a maneira pela qual um indivíduo se relaciona com uma regra ou com um sistema de regras e experimenta a obrigação de colocá-las em ação. (Revel, 2005, p. 45).

Em Foucault, esse modo de construir-se a si mesmo como sujeito ético se dá por meio de práticas de liberdade. Assim, um sujeito que é sujeitado por códigos e regras morais pode não conseguir construir-se como sujeito ético. A liberdade da qual Foucault fala aparece como um processo complexo que se engendra por meio de reflexão, prática e atitude. Nesse sentido, o

objeto ao qual se aplicam a reflexão, a prática e a atitude é o sujeito: nós mesmos enquanto seres historicamente determinados, em parte por relações de poder-saber, mas ao mesmo tempo, sujeitos a transformações, capazes de enfraquecer as fronteiras, os limites que nos constituem por meio de um trabalho sobre nós mesmos, em exercício prático crítico, um estética da existência. (Nascimento, Espaço Michel Foucault, 2010).

A proposta de Foucault repropõe a análise do campo político a partir da constituição ética dos sujeitos, ou seja, da produção da própria subjetividade. Nesse sentido, a ética e a estética da existência aparecem inteiramente conectadas. O tema da estética da existência, como produção inventiva de si, aponta não a volta de um sujeito universal e soberano, mas um sujeito que se constitui mediante práticas de sujeição, ou de uma maneira mais autônoma, pelas práticas de libertação. A estética da existência, na medida em que ela é uma prática ética de produção de subjeti- 
vidade é, ao mesmo tempo, assujeitada e resistente: é, portanto, um gesto eminentemente político (Revel, 2005, p. 44). Essa estética da existência não se situa num espaço vazio, mas no âmbito da experiência humana, por isso mesmo algumas escolhas são possíveis e outras não, já que elas estão vinculadas às dinâmicas do contexto sociocultural.

Segundo Foucault, o cuidado de si, o conhecer e o construir-se como sujeito ético/moral constituem uma prática antiga, que tem origem na tradição grega e cristã. Na tradição grega, o cuidado de si não aparece como uma prática isolada; ela sempre teve uma relação com o social, com o outro. Os cuidados de si que envolvia os cuidados com o corpo, com regimes de saúde, com meditações, não se constituíam em um exercício de solidão, mas de uma verdadeira prática social. Existiam práticas comuns nos cuidados que as pessoas tinham consigo como o fato de receber ajuda do outro, ou cuidar do outro. O cuidado de si, ou o cuidado que se tem com o cuidado que os outros devem ter consigo mesmo, aparece então como uma intensificação das relações sociais (Foucault, 2007b, p. 58). Na tradição cristã, a prática de si se dava pelo exame de consciência, na qual o indivíduo era levado a examinar sua vida pessoal, a se orientar para a conversão e a assumir um comportamento moral que dizia respeito a uma ética de domínio de si. Já nas dinâmicas de poder da sociedade moderna, Foucault revela que a constituição de si mesmo, como um sujeito ético que orienta as suas próprias ações, não parece ser algo pacífico.

Enquanto a ética antiga implicava em uma articulação bem estreita entre o poder sobre si e o poder sobre os outros e, portanto, deveria referir-se a uma estética da vida em conformidade com o status, as novas regras do jogo político tornam mais difícil a definição das relações entre o que se é, o que se pode fazer e o que o sujeito ético é obrigado a realizar (Foucault, 2007b, p. 91) 
No entanto, diante das novas regras do jogo político da sociedade moderna, que modificam as relações entre status, encargos, poderes e deveres, dois fenômenos podem ser produzidos. De um lado, há um forte acento de regras ou normas que fazem com que o indivíduo fixe sua identidade ou que venha a adequar-se o quanto possível a um determinado status, que se processa por meio de atitudes, gestos, vestimenta. De outro lado, existe a postura de quem busca fixar a sua identidade a partir de uma relação pura consigo mesmo.

Trata-se, então, de constituir-se e reconhecer-se enquanto sujeito de suas próprias ações, não através de um sistema de signos marcando poder sobre os outros, mas através de uma relação tanto quanto possível independente do status e de suas forças exteriores, já que ela se realiza na soberania que se exerce sobre si próprio (Foucault, 2007b, p. 92).

$\mathrm{O}$ ato de conduzir-se por si mesmo, ou de ter a soberania sobre os seus atos, implica também uma relação político-social, ou seja, é sabendo se conduzir bem, que ele saberá conduzir, como convém, aos outros (Foucault, 2007b, p. 95). Nesse caso, a arte de conduzir-se por si mesmo se tornava um fator político determinante.

Se na Grécia Antiga o cuidado de si não era uma atividade isolada e individual, a construção de si como sujeito ético, atualmente, também não pode ser vista como uma prática puramente individual, isolada e autossuficiente, já que ela envolve: a dimensão epistemológica, ligada a um saber compartilhado; a dimensão política, ou seja, ligada a um contato imerso nas relações de poder com, sobre e sob os outros. Desse modo, na perspectiva foucaultiana, o indivíduo não pode mudar a si mesmo sem mudar, simultaneamente, as relações consigo mesmo, as relações com os outros e as relações com a verdade (Nascimento, Espaço Michel Foucault, 2010). 
A noção de sujeito ético de Foucault que se subjetiva e se constrói a si mesmo, a partir do questionamento de si, do status do poder e das regras do jogo político, constitui uma nova forma de sentir, de pensar, de cuidar de si. É uma forma de estética do Eu e da vida. É uma nova subjetivação que se constrói na relação reflexiva com o conjunto das normas socioculturais. Essa noção de sujeito que se constitui na relação com os jogos de saber e de poder tem alguma relação com a noção de "sujeito como relação de si" de Alain Touraine, já que este autor também faz referência a um sujeito que se constitui assumindo a sua própria vida e os próprios atos. Touraine inclui a dimensão do cuidado de si que se volta para o outro, no entanto, o faz numa relação de resistência perante os processos ideológico-estruturais. Aprofundaremos essa visão de sujeito nos pontos que seguem.

\section{Considerações sobre a abordagem de Alain Touraine}

Alain Touraine é um dos grandes críticos da modernidade. É conhecido como o fundador da expressão "sociedade pós-industrial". Nessa sociedade, a resistência ao poder de gestão se apoia no sujeito. Para Touraine, a indústria cultural da sociedade industrial vai exercer controle, não pelas formas tradicionais, mas por novos mecanismos. Assim, os movimentos sociais surgem como uma forma de contestação às diferentes formas de controle social.

Desse modo, Touraine centrou o seu trabalho tomando como base a "sociologia da ação", tendo como principal interesse o estudo dos movimentos sociais, visando com isso mostrar as transformaçãoes sociais e culturais da sociedade moderna e industrial. Sua sociologia estabelece um diálogo crítico com os clássicos, sobretudo, Durkheim e Marx. Concebe que, na sociedade contemporânea, os conflitos sociais se generalizaram e 
obedecem a uma outra ordem, que não são mais as dinâmicas econômicas. Mesmo que a indústria não tenha desaparecido, os conflitos de classe e a relação trabalhador e proprietário dos bens da produção não estão mais no centro das dinâmicas da sociedade pós-industrial. Para Touraine, estamos presenciando a emergência de outras reivindicações sociais, não mais pautadas em características econômicas, mas culturais, como é o caso dos movimentos feministas, de identidade sexual, estudantil, ecológico.

O autor concebe a existência do sujeito enquanto contestação, isto é, do indivíduo que se rebela contra as condições sociais que lhes são impostas. O sujeito é, então, a construção do indivíduo como ator. Para esse sociólogo, não se pode separar o indivíduo de seu contexto social. Ele aponta uma tendência não mais de sujeição e predestinação, mas de um sujeito que se cria por si mesmo, um sujeito que se constrói na historicidade, ou seja, que se torna contestatório dentro de um contexto social. Nesse sentido, o movimento social é um esforço de um ator coletivo para se apossar dos valores, das orientações culturais de uma sociedade, opondo-se à ação de um adversário no qual esse ator está ligado, que tende a exercer controle sobre os indivíduos ${ }^{11}$.

Nas obras do autor em questão, é recorrente a ideia de igualdade e diferença vinculada à noção de direitos humanos, como uma nova condição de existência humana diante dos grandes desafios da sociedade contemporânea. Há o imperativo da necessidade de se combinar os processos de internacionalização com o direito de ser, ao mesmo tempo, igual e diferente. Daí a importância que este autor dá aos novos movimentos sociais e culturais, que emergem com preocupação ligada à identidade cultural. Para Touraine, os antigos paradigmas não dão mais conta dos sujeitos emergen-

11 As reflexões iniciais fazem parte de apontamento pessoal, feito durante as aulas da disciplina de Sociologia Contemporânea. 
tes, cujas ações estão centradas não mais na política e na sociedade, mas na cultura. Isso faz com que as lutas atuais não estejam mais focadas nos problemas políticos e sociais, mas culturais, e a busca pelos direitos culturais se torne um fator-chave do sujeito pessoal. Na visão do autor, nesse novo paradigma cultural as mulheres exercem um papel fundamental por serem elas as portadoras do que ele chama de sujeito pessoal.

Para Touraine, o modelo ocidental de modernização que conquistou o mundo, em nome da sociedade, começou a perder força quando os dominados se revoltaram contra os senhores representados pelos movimentos: operários, de libertação nacional, feministas e ecologistas. Esses movimentos abalaram a elite dirigente de proprietários, europeus, adultos do sexo masculino. Trabalhadores, colonizados, mulheres e minorias de diversos tipos criaram para si uma nova subjetividade. As vítimas, em certo momento, deixam de ser apenas vítimas; tomam consciência de sua situação, protestam e falam (Touraine, 2006, p. 99). Rejeitam a submissão, atribuem a si mesmo uma subjetividade e afirmam-se como seres de direitos, capazes de rechaçar a injustiça, a desigualdade e a humilhação (Touraine, 2006. p. 101). Tais grupos, de certa forma, mostram que este mundo não pode mais ser construído ao redor da conquista e da gestão das tensões mais fortes, mas a partir da busca de si mesmo e da resistência às forças impessoais. O autor acredita que essa forma de resistência traz dentro dela mesma uma afirmação de si, não apenas como ator social, mas como sujeito pessoal. Assim, para ele: a crise da sociedade pode nos salvar de uma catástrofe se esta levar à construção da idéia de sujeito, à busca de uma ação, que não procure nem o lucro, nem o poder, nem a glória, mas que afirme a dignidade de cada ser humano (Touraine, 2006, p. 102).

Sua postura é de que, diante de tantas ameaças externas, somos impelidos a buscar no interior de nós mesmos a nossa unidade de sujeitos. O sujeito é mais forte e mais consciente de si mesmo quando se defen- 
de contra os ataques que ameaçam sua autonomia e sua capacidade de perceber-se como um sujeito integrado, ou pelo menos lutando para sê-lo, para reconhecer e ser reconhecido como tal (Touraine, 2006, p. 112). Touraine passa a desenvolver a compreensão de um sujeito que se constrói a si mesmo, não somente como um sujeito coletivo, mas também como sujeito pessoal, como alguém que defende sua posição de identidade e de direitos que, no caso de Touraine, não chega a ser uma nova estética de si como em Foucault.

\subsection{A noção de sujeito pessoal em Alain Touraine}

$\mathrm{Na}$ atual conjuntura de economia globalizada com a persistência de certos imperialismos, colonialismo e de desigualdade social, segundo Touraine, é impossível não reconhecer a existência do sujeito que se posiciona contra o reinado do dinheiro e o aumento das desigualdades. É impossível também falar em direitos humanos sem reconhecer que, cada vez mais, os seres humanos avaliam seus atos e sua situação, em termos de criarem-se a si mesmos e de viverem como seres livres e responsáveis. O autor aponta a existência de um sujeito que se constrói por si mesmo, a partir da consciência de sua experiência no mundo, da luta pelo reconhecimento de si, como pessoa de direitos e, por meio de atos de resistências, constrói um sentido para a sua existência.

Quanto mais nossa vida depender de nós mesmos, tanto mais tomaremos consciência de todos os aspectos de nossa experiência. E cada vez que devíamos recuar enquanto atores sociais, nós nos fortalecíamos como sujeitos pessoais. Só nos tornaremos plenamente sujeitos quando aceitamos como nosso ideal reconhecer-nos - e fazer-nos reconhecer enquanto indivíduos - como seres individualizados, que defendem e constroem sua singularidade, dando, através de nossos atos de resistência, um sentido a nossa existência. (Touraine, 2006, p.123). 
Observa-se que o autor descreve a existência de um sujeito que não é somente coletivo, mas individualizado e reflexivo, capaz de analisar as condições sociais que lhes são impostas e de construir atos de resistência. Um sujeito que se volta para si mesmo como uma forma de se fortalecer diante das dinâmicas que oprimem e promovem a exclusão social. Essa ideia de sujeito pessoal evoca a luta social, como é o caso da consciência de classe, porém com um conteúdo diferente, privado de exterioridade e voltado para si mesmo, em cujo nível o conflito também existe. A concepção de sujeito desse autor é perpassada por duas ideias centrais que remetem à ação de resistência e da luta pela liberdade. O sujeito voltado para a construção de si mesmo se situa na ordem dos direitos humanos e dos deveres (Touraine, 2006, p. 119-121).

Esse sujeito é sempre percebido em situação contextual, em relação ao poder que ele possui ou ao qual está submetido, em relação com o outro, amigo ou inimigo. Entretanto, para o autor, é somente quando nos libertamos das representações de sujeito, tido como ator da história e portador de uma sociedade, que poderemos enxergar o verdadeiro rosto do sujeito, ou seja, o ator individual ou coletivo, que não mais é orientado pelos valores, pelas normas e pelos interesses da sociedade, mas por uma relação consigo mesmo ${ }^{12}$.

Na visão de Touraine, esse sujeito pode ser reconhecido tanto no indivíduo como na coletividade. Para ele, mesmo que um indivíduo esteja engajado em um movimento de luta social, ele está sempre a serviço da imagem dele mesmo, ou seja, na busca por constituir "sua razão de ser, seu dever e sua esperança" ${ }^{\prime 13}$.

12 Touraine (2006) menciona que, embora em seus estudos anteriores, em um período de transição, tivesse falado em sujeito histórico, atualmente prefere falar em sujeito pessoal, o qual não se reduz somente a casos individuais.

13 Ao defender a ideia de um sujeito que se constrói a si mesmo, Touraine (2006, p.137) se posiciona contra críticas que lhes são feitas e alega não estar elaborando um conceito liberal, uma vez que não tem a preocupação de colocar ênfase nas estruturas e nas formas de domi- 
Sua razão de ser, porque a idéia da criação ou da autocriação está sempre presente. Seu dever, porque a figura do sujeito impõe sua preeminência sobre todos os outros aspectos da vida pessoal ou coletiva. Sua esperança, porque esta é a contrapartida da criação. Quem se torna sujeito retorna a si mesmo, àquilo que confere sentido a sua vida, àquilo que cria a sua liberdade, sua responsabilidade e sua esperança. (Touraine, 2006, p.136, grifo meu)

Entretanto, Touraine deixa claro que nenhum indivíduo ou grupo carrega em si a totalidade do sujeito e, por isso, é mais correto afirmar que existe algo de sujeito em tal conduta ou em tal indivíduo (Touraine, 2006, p.137), já que a existência do sujeito sempre aparece remetida nas atitudes que envolvem a consciência de si, na luta e resistência diante das diferentes formas de violência, dominação e guerra. Se existe sujeito da resistência em face das forças do poder que aniquilam o ser humano, existe também o que ele chama de "não sujeito", aqui compreendido como aquele indivíduo que reproduz a dominação e a guerra, anulando o direito de o outro ser sujeito, justamente por ser incapaz de reconhecer no outro a existência do sujeito. Ele relaciona o "bem" ao sujeito e o "mal" ao "não sujeito". Existem aqueles que reconhecem o sujeito em si e nos outros, são os que fazem o bem, e àqueles que procuram matar o sujeito nos outros e em si mesmos: são os que fazem o mal.

$\mathrm{O}$ autor considera ser fundamental um olhar atento sobre as diferentes figuras de sujeito e as formas de subjetivação, a fim conhecermos bem as relações sociais. Acredita que pode existir uma sociologia do sujeito quando se encontram somente coações, impotência ou vítimas que resultam de forças e interesses sociais. O sujeito, tanto coletivo como pessoal, não pode ser visto somente como vítima do sistema ou da dominação,

nação social. No entanto, alega que na época do Welfare State e da social democracia, ao lado das ideologias do aparelho do Estado (capitalista ou comunista), certos movimentos sociais, correntes de ideias, esforços associativos já traziam em si a figura do sujeito. 
já que em meio aos processos de dominação ele também encontra maneiras para se construir como sujeito, como o autor evidenciou em sua pesquisa com as mulheres na França ${ }^{14}$.

Olhando para as formas como o sujeito emerge em diferentes partes do mundo, o autor afirma que este novo sujeito não alimenta mais a esperança em um progresso redentor, e muito menos surge como quem quer socorrer todos os atingidos pelas lógicas de dominação. Mas é um sujeito que chega à liberdade e à transparência por meio da relação mais direta consigo mesmo, que a modernidade lhe permite e, até, impõe (Touraine, 2006, p.139). Nesse sentido, acredita que o retorno a si mesmo que produz o sujeito começa bem perto do indivíduo, em sua relação com o próprio corpo. Desse modo, a noção de sujeito de Touraine se aproxima das concepções de sujeito ético de Foucault, quando este se refere ao dispositivo da sexualidade, como formador da subjetividade e da construção de si mesmo. Entretanto, na ética da vida o sujeito não necessita ser tratado como um ser de direitos, como condição de seu existir. O sujeito ético existe e se faz existir, ainda que não coloque como condição da sua existência a ideia de reivindicação de direitos.

O sujeito pessoal em Touraine não é um indivíduo prepotente que está acima da sociedade e muito menos um ser resultado de condicionamentos socioestruturais, mas é um indivíduo consciente de si e de seus direitos, ou seja, ele é o reconhecimento da singularidade de cada indivíduo que quer ser tratado como ser de direitos. Desse modo, o sujeito sendo ou não carregado pelo movimento social, ele é alguém que tem sua consciência de ator, já que na visão desse sociólogo nenhum indivíduo adere a um movimento simplesmente por um ato inconsciente. O indivíduo pessoal carrega em si o sujeito que age conscientemente e avalia as suas ações.

14 Mais detalhes, consultar o livro O mundo das mulheres, publicado no Brasil em 2007. 
A experiência de ser um sujeito se manifesta pela consciência de uma obrigação relativa, que não se relaciona a uma instituição ou a um valor, mas ao direito que cada um tem de viver e ser reconhecido como tal, em sua dignidade, naquilo que não pode ser abandonado sem privar a vida de todo o sentido. Assim, Touraine postula a ideia de que um indivíduo só se sente sujeito na medida em que tem consciência de sua responsabilidade perante a dignidade e a humanidade dos "outros" indivíduos. Dito em outras palavras, é reconhecendo os direitos humanos que um indivíduo reconhece as obrigações relativas a si mesmo. Tais experiências não acontecem em grande escala, ou se configuram como experiências heroicas, mas consistem em experiências familiares, de relações com pessoas mais próximas. São experiências que, individuais ou coletivas, se opõem à perspectiva da obediência às leis, aos costumes ou a ordens que vêm de autoridades centrais (Touraine, 2006, p. 157).

Touraine vê o sujeito não como uma mera projeção fraca de instituições sociais. Na sua visão, o que existe é a exteriorização do sujeito e do seu vínculo com uma experiência social coletiva ou com formas de organização e de práticas situáveis historicamente. Por isso mesmo, vê o sujeito como um princípio que escapa ao nível da organização social e da força mobilizadora das crenças. O sujeito não é apenas prisioneiro de algumas realidades, mas também capaz de atos libertadores (Touraine, 2006, p. 163). O domínio do sujeito aparece na medida em que este reflete mais sobre si mesmo e se coloca em posição de criador de si mesmo.

Essa noção de sujeito é retomada por Touraine em uma obra sua posterior $^{15}$, na qual ele insiste na necessidade de outro pensamento social

15 Essa obra se refere ao livro Pensar Outramente: o discurso interpretativo dominante, publicado no Brasil pela Editora Vozes, em 2009, na qual ele responde às críticas que são feitas à sua noção de sujeito, argumentando e reafirmando essa nova compreensão de sujeito. Considera que a sociologia precisa avançar na compreensão da sociedade atual, sem permanecer presa às velhas tradições, ou seja, ao discurso interpretativo dominante. 
e na urgência da construção de uma sociologia do sujeito. Nessa sociologia, o sujeito precisa ser compreendido como portador de direitos universais, sobretudo, do direito de ser reconhecido como autor autônomo, livre e responsável por suas condutas, e não em termos de utilidade social. Na sociedade atual, definida pelo autor como pós-social, a bandeira de luta do sujeito tem sido cada vez mais a defesa dos direitos individuais. De acordo com Touraine, o fato de a noção de sujeito pessoal ter uma compreensão distinta, ela não representa um rompimento com as concepções de cidadão e de trabalhador, que correspondiam às duas primeiras fases do processo de modernização.

É recorrente no pensamento de Touraine (2009) a ideia de que as lutas do sujeito têm uma referência universal, que são os direitos humanos, na qual reside o que ele chama de consciência de si. Assim, a relação consigo mesmo nada mais é do que a consciência de si e de seus direitos. Por mais que um indivíduo integre organizações ou movimentos sociais, a afirmação de si é sempre pessoal. Nos termos de Touraine, os seres humanos não são folhas mortas, pois eles sempre representam a sua situação por meio do uso da linguagem e, por isso, são capazes de dar uma significação diferente à do que a "sociedade gostaria de impor". Nas narrativas sobre quaisquer acontecimentos, seja de ordem do público-coletivo ou da vida cotidiana, é sempre o autor da narrativa quem expõe o sentido de cada experiência, ou da interpretação que faz de determinado acontecimento. A interpretação de um fato coletivo não é obra coletiva. Ela é a leitura do sentido que uma pessoa deu ao viver um fato, mesmo que coletivo. Por ser uma interpretação pessoal de um dado acontecimento coletivo, nem sempre se pode contar com o consentimento dos indivíduos que vivenciaram ou participaram do mesmo acontecimento.

Touraine (2009) menciona que figura do que ele entende ser o sujeito é encontrada nas relações cotidianas, uma vez que a vida das pessoas 
é feita de rotinas, de sofrimentos, de pequenas alegrias, bem como de grandes paixões ou raivas enraizadas. Nesse cotidiano, todos os esforços para sobreviver, para se redimir, para resolver problemas de trabalho ou de ordem familiar, são lugares onde o sujeito se constrói na afirmação de si, no direito de viver uma vida individual, no respeito ao outro, ao diferente, nas estratégias de proteção contra o poder das organizações e dos governos. Para Touraine, há mais grandeza, mais sacrifícios, mais criação do outro e de si na vida cotidiana do que nos grandes dramas sociais que são anunciados na mídia. Critica os sociólogos que procuram encontrar o sujeito somente em situações excepcionais ou em grandes projetos de transformação da ordem social, nos quais o sujeito aparece como parte de ações coletivas. Daí a insistência de Touraine para se pensar outramente, apostando em novas formas de compreensão do sujeito, descobrindoo, também, em outros lugares.

Atualmente é mais urgente e difícil buscar a presença do sujeito nas relações mais próximas e não somente nas coletivas nem nas mais organizadas. Não cederei a tentação de somente buscar o sujeito no cume das montanhas ou no cimo dos monumentos. O sujeito está no universo largamente inconsciente, nas relações entre pais e filhos, no universo dos amores e ódios, na construção da identidade pessoal e na consciência de pertencer a uma linhagem, a uma tradição, a uma comunidade, a uma história. O sujeito realmente não existe a não ser se for capaz de viver a tensão entre a pertença a grupos e à história, e a consciência de si. (Touraine, 2009, p. 168)

Nessa compreensão de sujeito, o autor afirma ser difícil distinguir rapidamente as relações que existem entre o mundo do sujeito e aquele da experiência vivida pelos grupos e pelas coletividades. Da mesma forma, o pensamento social não aparece desvinculado da ação coletiva que, numa análise sociológica, pode ser encontrada até em livros de poemas ou de história. A intenção e o esforço de Touraine é fazer com que a referência ao 
sujeito apareça, justamente, num mundo onde desaparecem as referências estruturantes em relação ao Estado e à instituição. Ao lado disso, argumenta que a ação do sujeito é encontrada nas condutas que podem ser organizadas ou não, desde que carreguem tanto o sentido da criação e do protesto como o sentido da continuidade e da fidelidade a uma herança. Tal compreensão evidencia que esse sujeito com capacidade de criação, capaz de protestar, consciente de ser parte e, também, continuador de uma tradição histórica, não pode ser pensado como um sujeito que se constitui sem referência às relações que envolvem a sociedade como um todo.

Vivemos em um mundo onde a consciência e a reflexão são partes integrantes do indivíduo. Por isso, de acordo com Touraine, o olhar que lançamos para nós mesmos nos ajuda a perceber uma dupla realidade, isto é, somente porque descobrimos o sujeito em nós é que poderemos descobri-lo no outro e, quando reconhecemos o outro, reconhecemos, também, a existência do sujeito nele. Sem o reconhecimento do outro, qualquer diferença, por mais simples que seja, pode tornar a comunicação impossível. Nesse sentido, o autor corrobora que as barreiras só poderão ser superadas quando os seres humanos se reconhecem sujeitos de direitos e, mutuamente, estabelecem laços de comunicação entre si. E isso só é possível graças à razão e ao respeito pelo caráter universal dos direitos individuais (Touraine, 2009, p. 192).

Os movimentos sociais e culturais são portadores desta nova figura de sujeito, que vai muito além da concepção de atores sociais, ligados entre si pela pertença a um grupo. Para o autor, a noção de sujeito pessoal, que pode ser coletiva ou individual, só tem conteúdo e importância quando permite descobrir o universalismo do sujeito. Por isso, um dos elementos importantes de análise do sujeito é de que

a elevação do indivíduo em direção a ele mesmo, enquanto sujeito só pode ser feita pelo reconhecimento do outro como sujeito: é ao reconhecer o outro como sujeito que 
posso me reconhecer eu mesmo como sujeito. Reconhecer o outro como sujeito é reconhecer a capacidade universal de todos se fazerem sujeitos. (Touraine, 2009, p. 196).

Para o autor, esse raciocínio nos faz sair de uma concepção que leva o sujeito ao isolamento, tornando impossível a comunicação com os outros autores. É reconhecendo no outro o sujeito que está em nós que se coloca a possibilidade de convivermos juntos com as nossas diferenças culturais, de gênero, de etnia e de crença religiosa. Assim, reconhecer que o "outro" também tem direito de ser sujeito seria hoje um caminho possível para se evitar certos comunitarismos, terrorismos ou, até mesmo, choque de civilizações.

\section{O sujeito ético e o sujeito pessoal: um olhar comparativo}

Ao destacar aspectos que fundamentam a noção de sujeito ético em Foucault e a noção de sujeito pessoal em Touraine, constatamos que a contribuição desses pensadores traz luz para a compreensão das dinâmicas que envolvem as relações sociais e a ação do sujeito, na sociedade do século XXI. Por isso, nesse ponto, mesmo que de forma breve e relativamente superficial, pretendemos elencar algumas convergências e diferenças acerca das noções de sujeito, para ver até que ponto a teoria de Touraine de fato se cruza com o pensamento de Foucault, bem como para discutir a importância de uma sociologia do sujeito no atual contexto de mudança sociocultural.

Convém lembrar que tanto Touraine como Foucault são intelectuais que pensam a partir de um mesmo contexto sociogeográfico, pelo fato de serem franceses. No entanto, as abordagens teóricas desses autores acerca do sujeito que se constrói a si mesmo, elaboradas no último momento de suas trajetórias intelectuais, embora apresentem certo cruzamento 
em alguns aspectos, deixam perceber singularidades e diferenças entre si. Enquanto Touraine analisa a ação e a emergência do sujeito no interior dos novos movimentos sociais, mesmo que em situações mais localizadas, essa ação de resistência, que pode ser coletiva ou individual, é compreendida no interior dos grandes processos de transformação socioculturais, mais amplos. Já Foucault enxerga o sujeito no interior das relações de poder e de saber que perpassam todas as relações sociais. Elege alguns espaços, que chamamos de microssociedade, como presídios, clínicas e as relações em torno da sexualidade humana, para compreender como as tecnologias de poder/saber e as tecnologias do eu produzem os sujeitos.

O objetivo de Touraine é evidenciar o sujeito, por isso ele procura elaborar uma teoria do sujeito. Considera ser necessário construir não mais uma sociologia dos sistemas sociais, mas uma sociologia dos sujeitos, que possibilita encontrar o sujeito não somente nos processos de dominação e de colonização, mas engajado nas lutas sociais e culturais, nas relações cotidianas, defendendo suas liberdades e seus direitos. Daí a sua preocupação em construir um novo paradigma para compreender os sujeitos e a sociedade, que não mais se definem em termos sociais, mas culturais. De outro lado, Foucault não esteve preocupado em construir uma teoria sobre o sujeito, mas sim em mostrar como nos constituímos como sujeitos. Para isso, ele se utiliza da metodologia da genealogia que o possibilita recuar ao passado para compreender os processos de subjetivação do presente. A sua construção teórica apresenta três modos de subjetivação que transformam os seres humanos em sujeitos, isto é, um indivíduo se torna sujeito por meio de práticas discursivas, disciplinares e subjetivantes. É interessante assinalar que, enquanto Touraine constrói o seu pensamento analisando as transformações da sociedade presente, Foucault recua para o passado para pensar o presente, mostrando como em cada contexto social e, também, em cada momento da história exis- 
tem diferenças no modo como os indivíduos são constituídos e se constituem em sujeitos.

Touraine, em seus escritos mais atuais, concebe uma visão de sujeito não apenas como um ator social coletivo, mas também como um sujeito individual, voltado para uma relação consigo mesmo. Esse sujeito existe sempre enquanto contestação, como indivíduo que se rebela contra as práticas de dominação em contextos sociais específicos. O sujeito pessoal se forma pelo desejo de escapar das forças, das regras, dos poderes que impedem o indivíduo de ser ele mesmo; das forças e dos poderes que buscam reduzir o indivíduo a um componente do sistema, por meio do controle de sua atividade e de suas interações sociais. Nessa visão, o sujeito passa a ser portador de conflito, cuja força mobilizadora opera no interior do próprio indivíduo. Desse modo, Touraine mostra que a ação do sujeito é sempre individual. Mesmo que ele esteja envolvido numa ação coletiva, se sente defensor de um direito universal. A questão-chave desse sujeito é a luta pelos direitos culturais ou individuais e a resistência aos poderes que querem negar a existência do sujeito. São determinadas condutas do indivíduo que visibilizam o sujeito, uma vez que ele só existe na medida em que houver a consciência de si e a resistência diante das diferentes formas de violência, dominação e guerra. Enfim, a consciência de sujeito em Touraine é formada pela combinação de três elementos que são fundamentais: a relação de si mesmo como um indivíduo portador de direitos fundamentais, a entrada consciente no conflito contra as forças dominantes que negam o direito e a possibilidade de agir como sujeito e a concepção que cada indivíduo possui de si, como sujeito (Touraine, 2006, p. 126).

Assim como em Touraine, Foucault apresenta uma nova compreensão de sujeito nas suas últimas obras, ou seja, ele passa da concepção de um sujeito disciplinado ou normalizado para um sujeito que se produz na relação consigo mesmo, por meio de tecnologias de si. No entanto, 
o sujeito constituído na experiência, por tecnologias de si, ou o sujeito ético, em Foucault, não está de todo desconectado das noções do sujeito produzido nas relações pelas tecnologias de saber e poder, uma vez que, nas técnicas de si, também perpassam relações de poder. Isso porque o indivíduo se autoexamina a partir das ciências, das regras. Na tradição grega e cristã, eram as técnicas que os indivíduos assimilavam que permitiam a autorreflexão. Em Foucault, a constituição do sujeito não se dá a "partir do nada", mas sempre no contexto de um conjunto de normas que precedem e excedem ao sujeito. É nesse contexto limitador e gerador de possibilidades que se torna possível a autorrealização ética, como parte de uma operação mais geral da crítica ao estabelecido.

Tanto em Foucault como em Touraine a produção do sujeito, a partir de uma relação consigo mesmo, aparece como uma condição de resistência política que permite ao sujeito uma afirmação de si e de sua própria identidade. Em Foucault, esse processo de produção do sujeito, como expressão de resistência, é conhecido como subjetivação ética e, em Touraine, alude ao ator social que se transforma em sujeito pessoal, por meio de um retorno a si mesmo e que se dá pela consciência de ser sujeito de direitos, podendo ser coletivo ou individual. Entretanto, essa resistência se dá de forma distinta para cada autor. Em Touraine, ela aparece numa relação de conflito contra os poderes externos ou forças impessoais que impedem ao indivíduo se reconhecer como sujeito de direito. É uma resistência à opressão, à guerra, à violência, assim como aos micropoderes que se travam nas relações mais cotidianas, nas quais os indivíduos livremente optam por "desobedecer" certas normas institucionais ou fundadas em uma autoridade distinta. Nesse último ponto, há certa aproximação com Foucault, já que nesse autor a resistência se relaciona às normas e aos discursos institucionais, que nas microrrelações tendem a sujeitar os indivíduos. A resistência se dá em um enfoque mais interno, na medida 
em que diz respeito às estratégias que o sujeito encontra para uma nova invenção de si, contrapondo-se ao poder normatizador dos códigos sociais de conduta, presentes nos discursos hegemônicos. A luta se dá com as normas e os discursos, na medida em que o sujeito questiona um "regime de verdade" que não possibilita o seu próprio reconhecimento ou que não está ao seu alcance. Nesse sentido, para Foucault, as tecnologias de poder e saber e as tecnologias do eu tanto produzem indivíduos e grupos governáveis como também focos de resistência que permitem aos indivíduos ou grupos gerarem processos de transformação. É nos espaços de liberdade, ou de ação livre que o indivíduo se constitui como sujeito ético. Para esse autor, a relação de si para consigo, formadora de subjetividade ética, requer a existência de atos de liberdade e de resistência.

Quanto às noções de sujeito, constata-se certo cruzamento no pensamento dos dois autores, sobretudo porque as ideias de resistência, de liberdade e de reflexividade são aspectos significativos para pensar o sujeito. Em ambos, a transformação das relações se dá pela resistência aos poderes e por atos livres do sujeito. Em Foucault, os atos de liberdade se engendram pela reflexão e resultam em posturas ou atos criativos que tendem a transformar as relações, ou seja, enfraquecer as fronteiras do poder que age nos indivíduos por meio das práticas discursivas. No final de sua vida, esse intelectual insistia na ideia de que o sujeito precisava libertar-se das relações do poder discursivo e disciplinador que agia por meio das relações microssociais e individualizadas, reforçando e sustentando, de forma velada, as dinâmicas do poder central. Esse processo só seria possível mediante atos de liberdade do sujeito que, guiados pela ética, funcionariam como um foco de resistência. Com isso, o autor aponta para a existência de um sujeito que não é só produzido por práticas de sujeição, mas também por práticas de libertação.

De igual modo, em Touraine, o sujeito não parece produzido pelas forças dos deuses e da sociedade, mas pela reflexão de si mesmo e de sua 
condição de criador, ou seja, ele não é somente prisioneiro, mas um ser capaz de atos criadores. Para o autor, os seres humanos não são apenas vítimas de um sistema, mas pelo seu domínio de reflexão e de consciência de si, se constituem criadores de si mesmo. É disso que resultam a resistência e a liberdade do sujeito, cuja ideia é recorrente em Touraine e em Foucault.

Quanto ao aspecto da reflexividade, em Foucault ela surge quando se estabelece uma relação com os códigos morais, como resposta à indagação do outro com que o sujeito fala. Assim, o sujeito se torna reflexivo no contexto da geração de um relato narrativo sobre si mesmo, que se realiza num processo de interação com o outro. Essa reflexividade se dá por meio das técnicas de si, as quais no decurso da história foram se modificando e se diferenciando, de acordo com a dinâmica dos contextos culturais. No passado, quando um indivíduo era levado a meditar sobre a sua conduta, registrar o seu pensamento, averiguar o estado de sua alma ${ }^{16}$, ele não só refletia, mas também realizava uma ação ao colocar em prova a sua conduta na relação com os outros. Desse modo, essas práticas não fechavam o indivíduo a si mesmo, já que exerciam influência na sua conduta social, na convivência com os outros. Hoje, de acordo com o autor, as práticas de si, que moldam o sujeito ético, continuam existindo nos conselhos que recebemos dos outros, no diálogo terapêutico e nas práticas e iniciativas do cotidiano, que possibilitam a reflexão sobre a própria vida, sobre as relações que estabelecemos com os outros e sobre as estratégias cotidianas que utilizamos para reagir contra os poderes e discursos que, na sociedade atual, buscam disciplinar e controlar os indivíduos. Assim, não há como negar que as práticas de si, fundadas na reflexividade do indivíduo moderno, são também práticas sociais, ou ação social do sujeito, na medida em que

16 Essas práticas se davam por meio do autoexame e do cuidado de si. Também denominadas técnicas de si. 
se voltam para as relações de convivência social com os outros, as quais se traduzem, também, em atos de resistência e de liberdade.

Enquanto em Foucault a reflexividade se expressa por meio das técnicas de si, que faz do indivíduo um sujeito ético ao se posicionar diante dos códigos e normas de conduta social, em Touraine essa reflexividade está diretamente vinculada ao que ele chama de consciência de si, que passa por uma relação reflexiva sobre si, na qual o sujeito se reconhece como criador de si, capaz de nomear-se, de desenhar a sua autoimagem, de colocar limites às suas pertenças institucionais, de avaliar os seus atos, de ser livre e responsável e de engajar-se socialmente. Assim, é pela consciência de sua experiência no mundo, da luta pelo reconhecimento de si, como pessoa de direitos e, por meio de atos de resistências, que o indivíduo constrói um sentido para a sua existência. Destarte, esse sujeito individual ou coletivo é quem analisa as condições sociais que Ihes são impostas e constrói atos de resistência, sempre com referência aos direitos universais. É, então, uma reflexividade que emerge sempre na referência ao 'outro' ou às dinâmicas sociopolíticas. Assim, a compreensão do sujeito voltado para a construção de si mesmo, que faz de si a maneira de sua conduta e de sua ação, é tida como uma estratégia de integração, de fortalecimento e de resistência diante das dinâmicas sociais que, em Touraine, oprimem, excluem e impedem o ser humano de ser sujeito e, em Foucault, produzem indivíduos normalizados e disciplinados. São concepções muito próximas com pequenas distinções, mas que centralizam o sujeito e os espaços de liberdade que o indivíduo encontra para conduzir os processos de subjetivação, no interior das dinâmicas sociais.

Tanto em Foucault como em Touraine, a reflexividade incorpora a narrativa da experiência de si, de um sujeito que se coloca pela sua verdade, que reflete sobre sua conduta e sua ação. É pela narrativa que o sujeito expõe o sentido de suas experiências e faz a sua interpretação sobre 
os fatos coletivos, nos quais se encontra envolvido. A narrativa é sempre uma interpretação individual, pela qual o sujeito relata o sentido de sua experiência, mesmo que esta se dê na coletividade. É a voz do sujeito que se faz ser ouvida. No entanto, a constituição de si está sempre implicada numa temporalidade social que excede as suas próprias capacidades narrativas. Nesse sentido, Butler (2009) menciona que um "eu", mesmo que procure dar conta de si, não tem uma história própria, que não seja também a história de uma relação com um conjunto de relações ou de normas sociais. Nesses termos, por meio da narrativa, o sujeito dá coerência ao que ele é, expondo a sua experiência individual, que é também socialmente compartilhada.

É importante mencionar que, em Foucault, o indivíduo constrói a sua subjetividade na experiência existencial, buscando a verdade sobre si mesmo e deliberando eticamente ${ }^{17}$ sobre as normas, por meio de técnicas de si, ao passo que, em Touraine, a subjetivação passa pela consciência de si e da vontade de ser reconhecido como um ser de direitos, que o leva a lutar e a se opor às forças que destroem o sujeito.

$\mathrm{O}$ aspecto do poder com o qual o sujeito se confronta e cria suas estratégias de resistências nos processos de subjetivação aparece de maneira distinta nos dois autores. Em Touraine, o poder é compreendido como força de dominação que explora, oprime e nega os direitos dos indivíduos e a condição de ser sujeito, cuja resistência se dá por meio da contestação que pode ser tanto pessoal como coletiva. Já em Foucault, o poder tem relação direta com o saber e com as normas sociais e é tido como uma força produtora de subjetividades, capaz de produzir sujeitos passivos que agem de acordo com o status quo, ou sujeitos éticos,

17 Em Foucault, essa deliberação ética está associada à operação da crítica, que consiste em mostrar o limite das normas na constituição do sujeito. 
quando capazes de atos de resistência e criatividade perante as dinâmicas do poder normatizador. É um poder que produz efeitos mais próximos do indivíduo e do seu corpo. Entretanto, seja como força produtora de efeitos, seja como força de dominação, os dois autores concebem que as relações de poder não estão presentes somente em instituições centrais ou nos processos mais amplos da globalização, mas perpassam também as pequenas relações do cotidiano, nas quais os indivíduos se constituem sujeitos, relacionando-se de forma reflexiva consigo mesmo.

Em Foucault, não existe uma concepção de sujeito universal, já que para ele há diferentes modos pelos quais o sujeito se constitui, seja por práticas discursivas, disciplinares ou de subjetivação. Todas se dão no interior de microrrelações sociais de poder e se diferenciam em cada momento histórico. Assim, se a constituição do sujeito se dá no interior das dinâmicas contextuais particulares e por diferentes modos, não se pode dizer que o sujeito é pensado a partir de um princípio universalista mais geral, embora a vontade de saber, por onde perpassam as dinâmicas que envolvem saber/poder e o conhecimento de si, tem um sentido universal por estar presente em cada ser humano. Já Touraine insiste na ideia de buscar o sujeito não só no interior dos grandes processos coletivos e sociais, mas, sobretudo, nas relações mais próximas, nas relações do cotidiano, nas relações consigo mesmo, nas relações com o seu corpo e com a própria sexualidade. Esse sujeito pessoal se constitui em experiências localizadas e concretas, mas sempre em referência aos direitos universais, ou seja, é um sujeito consciente de ser portador de direitos individuais e culturais que precisam ser respeitados. É um sujeito que se constitui na experiência vivida, na capacidade de viver com as tensões que emergem pela consciência de pertencer a um grupo e a uma história e, de outro lado, pela consciência de si e de seus direitos. Para Touraine, é a consciência universal de ser sujeito de direitos e a capacidade de ver 
no outro também um sujeito de direitos que permitem conviver com as diversidades e evitar certos comunitarismos. Desse modo, ao admitir a existência da diversidade de sujeitos culturais, Touraine se afasta de uma concepção de sujeito único e universal. No entanto, a compreensão de sujeito pessoal desse autor só tem conteúdo e importância por permitir descobrir o universalismo do sujeito, sejam quais forem as condições históricas deste sujeito. Nesse sentido, o próprio autor afirma que uma das características do sujeito pessoal é o fato de ser universalista, no sentido de que os direitos universais devem ser defendidos em todas as situações (Touraine, 2009, p, 225).

Contudo, Touraine parece romper com uma perspectiva universalista quando enfatiza a constituição do sujeito por meio de experiências concretas e localizadas, com referência aos direitos humanos. No entanto, ao reivindicar a condição universal do sujeito, pode nos levar a questionar até que ponto ele não repõe, de forma abstrata e formal, certo eurocentrismo na ideia de sujeito.

As concepções de sujeito de Touraine e Foucault, sobretudo nos seus últimos escritos, têm recebido algumas críticas por serem consideradas demasiadamente individualistas e personalistas, cuja força estaria centrada num eu, um tanto prepotente, capaz de dar rumo à sua própria história, desvinculado de um contexto sociocultural mais amplo, que exerce influência nas relações sociais. Entretanto, um estudo mais aprofundado nos revela que a concepção identificada como sujeito ético em Foucault e sujeito pessoal em Touraine possui, sim, fortes vínculos com as dinâmicas sociais, uma vez que o sujeito se constitui no interior de contextos socioculturais, localizados e concretos. A forte ênfase no sujeito não o isola das relações sociais, mesmo que este seja construído na experiência, por meio das técnicas de si ou pela consciência de si, na referência aos direitos culturais. A seguir, destacamos alguns aspectos nos 
quais é possível constatar os vínculos sociais implicados no processo da constituição do sujeito em Foucault e Touraine.

Por primeiro, é notável que a noção do sujeito que se constitui por meio de uma relação consigo mesmo não se processa independentemente das relações e das forças sociais, uma vez que esse modo de subjetivação é, também, uma estratégia de resistência política às formas de poder que agem sobre os indivíduos, seja por processos discursivos, disciplinares, normativos seja por forças externas que ameaçam os direitos humanos, que podem tanto dominar como objetivar os indivíduos. No entanto, é por meio das estratégias de resistências que o sujeito produz atos de liberdade, de reflexão, de criação de si e de ação. Tais atos o transformam pessoalmente e, ao mesmo tempo, provocam a transformação das relações com os outros. Nota-se que esses autores dão maior acento ao sujeito e não às forças das instituições sociais. Entretanto, a constituição de si está sempre implicada num tempo social específico, que molda o sujeito por meio de um processo de interação com circunstâncias sociais concretas.

Num segundo aspecto, nota-se que o sujeito ético ou pessoal se molda, realiza as suas experiências e age em contextos sociais concretos. Nesse sentido, em Foucault, a existência do sujeito ético está situada no âmbito da experiência humana local, em que algumas escolhas podem ser possíveis e outras não, já que elas integram as dinâmicas do tecido social. Em Touraine, a ação do sujeito se encontra em condutas que, organizadas ou não, carregam o sentido da criação e do protesto, mas também a consciência da continuidade de uma tradição histórica. Destarte, não se pode pensar em um sujeito que se constitui a si mesmo sem referência às relações e aos contextos socioculturais.

Por último, a noção de sujeito construída por Touraine, como um sujeito consciente de si, que se reconhece como sujeito de direitos, não é nada individualista, no sentido de bastar-se a si mesmo, já que é reconhe- 
cendo-se como sujeito de direitos que se pode reconhecer o sujeito que está no outro. Essa condição impulsiona o indivíduo a sentir-se responsável e comprometido com a luta, tanto pela sua dignidade e humanidade como pela dignidade do outro. É claro que, na noção de sujeito de Touraine, as relações sociais estão imbricadas, uma vez que no envolvimento e no engajamento social se constroem as relações de solidariedade, de amizade entre sujeitos que se mobilizam por terem a consciência de serem sujeitos de direitos. Tal compreensão se aproxima da ideia de sujeito ético de Foucault, no qual as técnicas de cuidado de si, nas suas origens, além de envolver a participação de outras pessoas, se voltavam para o cuidado com os outros. Isso porque, na tradição grega, somente o sujeito capaz de cuidar de si era também capaz de dirigir e cuidar da cidade. O mesmo podia se verificar na tradição cristã, já que a confissão, como autoexame, era uma técnica que se dava por meio da mediação de outra pessoa. Isso também se observa na sociedade moderna, na qual o conhecimento de si se produz por meio de um processo de interação com o médico ou o psicólogo ou, ainda, por meio das práticas cotidianas de confronto com o outro. Por meio dessas técnicas, o sujeito não se produz para si mesmo, mas se volta para o outro, na medida em que melhora a sua conduta e, consequentemente, as relações que estabelece com os outros. Desse modo, a construção de si, como sujeito ético, não pode ser pensada como uma construção isolada, mas inserida nas dinâmicas sociais. Isso porque, como bem assinalou Wanderson Flor do Nascimento (2010), envolve o saber compartilhado e a dimensão política que aparece vinculada a um contato imerso nas relações de poder com, sobre e sob os outros, ou seja, pela perspectiva foucaultiana, um indivíduo não pode mudar o seu modo de ser, sem mudar as relações com os outros e as relações com a verdade.

Essas questões demarcam a validade teórica e epistemológica das construções em torno da noção de sujeito desses autores contemporâneos 
que, mais do que qualquer coisa, apontam uma nova luz para a teoria social, sobretudo na compreensão dos processos de subjetivação dos indivíduos, em sua relação com as dinâmicas socioculturais.

\section{Considerações finais:}

é possível uma sociologia do sujeito?

A reflexão sobre as contribuições teóricas acerca da noção de sujeito ético em Foucault e de sujeito pessoal em Touraine aponta para outras perspectivas teóricas no interior do debate sociológico. São possibilidades que emergem, interrogam e trazem luz para se repensar as ferramentas que utilizamos na compreensão da sociedade moderna, em contexto de transformações complexas. Como cientistas sociais, mais do que simplesmente reproduzir paradigmas já consagrados, que deram conta de problemas sociais em contextos específicos, precisamos, sim, nos abrir e ousar refletir sobre as possibilidades que outras perspectivas teóricas trazem para o conhecimento social. Faz-se necessário buscar paradigmas que deem conta da realidade sociocultural atual, sobretudo no que se refere às relações que se estabelecem entre os indivíduos e as estruturas sociais. É nessa direção que podemos incluir o esforço feito por Foucault e Touraine, principalmente quando esses apontam para um paradigma com centralidade no sujeito. Indubitavelmente, as concepções teóricas das noções de sujeito desses autores, que aqui expusemos, mais em termos de definições, apontam para implicações epistemológicas e metodológicas que merecem ser aprofundadas em outros estudos possíveis.

Entre os distintos aspectos teóricos de Foucault e Touraine, mencionados neste trabalho, a dimensão reflexiva do sujeito moderno, por meio da qual ele interpreta o sentido de suas ações e experiências, revela que estamos diante de um sujeito que não é mais somente produto das institui- 
ções sociais e das relações de poder, mas que se constitui como um sujeito reflexivo, capaz de se conhecer, de mudar a sua conduta, transformando, ao mesmo tempo, as relações sociais que estabelece com os outros.

É imperativo ter em conta que um sujeito é sujeito à proporção que se torna capaz não apenas de ter vida própria, mas de constituir um outro 'nós', um outro coletivo, de preferência mais inclusivo". Não se trata de um sujeito ensimesmado ao extremo, a ponto de se portar de forma insensível em relação aos demais. (Floriani, et al, 2008).

Essa compreensão de sujeito do autor anteriormente citado, de certa forma, está presente nas noções de sujeito construídas por Foucault e Touraine. Eles apontam para a existência de sujeitos não mais como vítimas ou resultado passivo das relações de poder, como alguns paradigmas costumavam compreendê-los no conjunto dos processos sociais. Mas, sim, sujeitos de reflexão e, por isso, de resistência à violência, à guerra ou de resistência aos efeitos das microrrelações de poder. São sujeitos capazes de atos éticos e liberdade criativa diante do poder normatizador (Foucault) ou sujeitos que compartilham saberes e se engajam em lutas coletivas que garantem legalmente os seus direitos (Touraine).

Pode-se dizer que nas duas concepções teóricas o sujeito não aparece como um sujeito vazio ou fragmentado, mas um sujeito integrado em si mesmo, pela afirmação de si e de sua identidade, seja pela resistência às forças sociais que exclui e domina, ou pela resistência aos poderes que normatiza, disciplina ou controla. Não é um sujeito isolado, mas voltado para o outro, comprometido com o outro, tanto por transformar as suas condutas na relação de cuidado com o outro quanto por reconhecer no outro um sujeito de direito. Não é um sujeito que só pode ser encontrado no coletivo e nos grandes acontecimentos históricos, mas é um sujeito pessoal, consciente de si, reflexivo, resistente e criativo, que se encontra nas experiências do cotidiano, na relação consigo mesmo e nas pequenas relações sociais e institucionais. 
A construção da noção de sujeito ético e de sujeito pessoal se vincula aos processos de transformação sociocultural e ao esforço que cada um faz para compreender o indivíduo no interior da sociedade contemporânea, em constante mudança. É também um esforço para a construção de bases teóricas que permitem olhar para as sociedades modernas a partir da centralidade do sujeito, cuja contribuição ganha força no debate sociológico, especificamente, acerca da ação social em face das instituições sociais.

Enfim, as abordagens sobre as noções de sujeito de Touraine e de Foucault, cada uma com suas diferenças epistemológicas, se apresentam como ferramentas teóricas, com as quais "as vozes" de sujeitos concretos, historicamente esquecidos, silenciados ou excluídos dos processos históricos, podem ser ouvidas e problematizadas pelos sujeitos do conhecimento. São contribuições que permitem fortalecer e legitimar a importância de uma sociologia do sujeito. Uma sociologia que não recorre aos grandes fenômenos históricos, mas coloca em cena o esforço do sujeito que, em meio às contradições sociais, culturais, econômicas, políticas e pessoais, reflete, toma consciência de si e confere sentido às suas experiências e práticas sociais.

\section{Referências}

BUTLER, Judith. Dar cuenta de si mismo: violencia ética y responsabilidad. Buenos Aires: Mutaciones, 2009.

FLORIANI, Dimas et al. Para pensar a 'subjetividade' no debate do sócio-ambientalismo. In: ENCONTRO NACIONAL DA ANPPAS, 4, 2008, Brasília - DP. Anais eletrônicos ANPPAS. Brasília: ANPPAS, 2010. Disponível em: <http://www. anppas.org.br/encontro4/cd/ARQUIVOS/GT15-968-766-20080518224342. pdf $>$. Acesso em: 09 de jul.2010.

FOUCAULT, Michel. Microfísica do Poder. 14aㅡ Ed. Rio de Janeiro: Edições Graal, 1999a.

FOUCAULT, Michel. História da sexualidade: a vontade de saber. 13a Ed. São Paulo: Edições Graal, 1999b. 
FOUCAULT, Michel. A hermenêutica do sujeito. São Paulo: Martins Fontes, 2004.

FOUCAULT, Michel. História da sexualidade: o uso dos prazeres. 12ª Ed. São Paulo: Edições Graal, 2007a.

FOUCAULT, Michel. História da sexualidade: o cuidado de si. 9ạ Ed. São Paulo: Edições Graal, 2007b.

FOUCAULT, Michel. As técnicas de si. WEB - Textos de Foucault em Português. Paris: Gallimard. 1994. Vol. IV, p. 783-813. Disponível em: < http://www.unb.br/ fe/tef/filoesco/foucault/biblio.html>. Acesso em: 13 nov. 2008.

LACERDA, Inês Araujo. Foucault a critica do Sujeito. 2a Ed. Curitiba: Editora UFPR, 2008.

NASCIMENTO, Wanderson Flor do. Nos rastros de Foucault: Ética e subjetivação. In. Espaço Michel Foucault. Link: Olhares Foucaultianos. Disponível em: <www. filoesco.unb.br/foucault>. Acesso: 06 ago. 2010.

REVEL, Judith. Foucault: conceitos essenciais. São Carlos: Claraluz Editora, 2005. TOURAINE, Alain. Um novo Paradigma para compreender o mundo hoje. $3^{\mathrm{a}}$ Ed. Petrópolis: Editora Vozes, 2006.

TOURAINE, Alain. Pensar Outramente: o discurso interpretativo dominante. Petrópolis: Editora Vozes, 2009.

Recebido em: 06/07/2011

Aceite final: 18/10/2011 